\title{
EXAME MICROBIOLÓGICO DE SORVETES NÃO PASTEURIZADOS
}

Deise Pasetto Falcáo* Gilberto Salgado Filho**

Nair Keiko Nishida **

Solange Rodas Borges**

FALCAO, D. P. et al. Exame microbiológico de sorvetes não pasteurizados. Rev. Saḍde públ., S. Paulo, 17:2-8, 1983.

RESUMO: Realizou-se exame microbiológico em 24 amostras de sorvetes năo pasteurizados, todos preparados de maneira não industrial e a base de leite (creme, nata, chocolate), fabricados por 12 sorveterias diferentes da cidade de Araraquara, SP. Colheram-se duas amostras de cada sorveteria com intervalo de 15 dias entre as colheitas. Realizaram-se as seguintes provas: contagem de bactérias aeróbicas ou facultativas mesófilas e psicrófi]as e de Staphylococous aureus; determinação do Número Mais Provavel (NMP) de coliformes totais e fecais e da presença de Salmonella. As técnicas utilizadas foram aquelas convencionalmente usadas para tais determinações. Não foi encontrada Salmonella em nenhuma das amostras e de cerca de 16,6\% delas isolou-se Staphylococcus aureus. Em proporçōes variáveis verificou-se a presença de microrgarnismos deteriorantes e daqueles indicadores de poluição de origem fecal.

UNITERMOS: Sorvete. Alimentos, contaminação. Microbiologia.

\section{INTRODUÇAO}

O controle microbiológico de sorvetes é de fundamental importância e por não sofrer qualquer processo de cocção ou esterilização após seu preparo final, como acontece com outros alimentos, pode se constituir num veículo de disseminação de microrganismos causadores de toxi-infecções. Os sorvetes contêm a flora microbiota dos ingredientes utilizados na sua preparação e aqueles à base de leite e ovos são potencialmente perigosos à saúde, pois se constituem em ótimos meios de cultura para a maioria dos microrganismos incluindo os patogênicos.
O envolvimento de sorvetes na transmissão de doenças tem sido demonstrado com frequiência em países onde é realizado controle rigoroso de alimentos. Nos Estados Unidos, Armstrong e col. ${ }^{3}$ relatam um grande surto de gastrenterite envolvendo 1.790 pessoas que haviam participado de 14 diferentes banquetes: isolaram Salmonella typhimurium e outros dois sorotipos de Salmonella das fezes de todos os doentes. Estudos epidemiológicos revelaram que 0 alimento envolvido era uma sobremesa gelada à base de sorvete, produzida por uma mesma indústria, e, que $o$ ingrediente

* Do Departamento de Ciências Bio-Clinicas da Faculdade de Ciências Farmacêuticas -"Campus" de Araraquara - UNESP - Rua Expedicionários do Brasil, 1.621 - 14800 Araraquara, SP, Brasil.

* Alunos estagíários do Departamento de Alimentos e Nutrição da Faculdade de Ciências Farmacéuticas - "Campus" de Araraqua - 14800 - Araraquara, SP, Brasil. 
FALCAO, D.P. et al. Exame microbiológico de sorvetes não pasteirizados. Rev. Saúde publ., S. Paulo, 17:2-8,1983.

contaminado com salmonela era gema de ovo não pasteurizada empregada no preparo do sorvete. Gunn e Markakis 18 descrevem a ocorrência de 22 surtos de salmonelose no periodo de 1966 a 1976, nos Estados Unidos, associados à ingestão de sorvetes caseiros, sendo que $S$. typhimurium foi a causadora de $45 \%$ dos surtos. Na Ilha de Trindade, Caribe, em 1971, ocorreu um surto de febre tifóide, envolvendo 132 pessoas, também relacionado à ingestão de sorvetes comercializados no país ${ }^{25}$.

Vários são os relatos dos serviços de Saúde Pública dos Estados Unidos e Canadá sobre casos de toxi-infecções por microrganismos diversos, principalmente salmonelas, ligados à ingestão de sorvetes ${ }^{4-12,19,20}$.

Chaineux e Jacquemim ${ }^{13}$ e Chaineux e col.14 mostram o elevado grau de contaminação de sorvetes vendidos na Bélgica $e$ Luxemburgo. Na Itália, Annino e col. ${ }^{2}$ isolaram $E$. coli em sorvetes e Frezza e col.16 constataram a presença de coliformes em 88\% das amostras de sorvetes que examinaram.

No Brasil, Taunay ${ }^{24}$, em 1968, relatou a ocorrência de um surto de gastrenterite no Amapá, causado por Salmonella paratyphi $C$, veiculado por sorvete. $O$ autor identificou 26 cepas de salmonelas das quais 25 foram isoladas dos pacientes e uma de leite em pó enlatado, usado na preparação do sorvete. Todas as 26 cepas eram de $S$. paratyphi $C$, confirmando a origem da epidemia, uma vez que todos os doentes haviam consumido - referido sorvete. Existe ainda em nosso país outro trabalho sobre contaminação de sorvetes, realizado por Joly ${ }^{22}$, que ao analisar diferentes amostras isolou uma flora contaminante variada. Como ocorre com outros alimentos, também para comestiveis gelados existem padrōes microbiológicos estabelecidos pela Comissão Nacional de Normas e Padrões para Alimentos do Ministério da Saúde ${ }^{23}$.

O objetivo da presente pesquisa é verjficar a presença de Salmonella, realizar contagens de bactérias aeróbicas ou faculta- tivas mesófilas e psicrófilas e de Staphylococcus aureus e determinar o Número Mais Provável (NMP) de coliformes totais e fecais em sorvetes não pasteurizados, preparados em escala não industrial, na cidade de Araraquara, SP, e comparar os resultados obtidos, quando possível, aos padrōes estabelecidos pela legislação em vigor.

\section{MATERIAL E METODOS}

\section{Material}

Foi constituido por 24 amostras de sorvetes não pasteurizados, todos à base de leite (nata, creme, chocolate), fabricados de maneira artesanal, por 12 diferentes sorveterias na cidade de Araraquara. Colheram-se duas amostras em cada estabelecimento com intervalo de 15 dias entre cada colheita. As amostras eram adquiridas como para consumo, em copos plásticos com capacidade de $100 \mathrm{ml}$, fornecidos pelos estabelecimentos. Uma vez adquiridas eram colocadas em caixa de material isotérmico "ISOPOR" contendo blocos de gelo e levadas ao laboratório, onde eram conservadas na geladeira a $4^{\circ} \mathrm{C}$ até descongelarem, quando então iniciava-se a análise microbiológica.

\section{Preparo das amostras}

Pesavam-se $10 \mathrm{~g}$ do sorvete liquefeito $\mathrm{e}$ misturava-se a $90 \mathrm{ml}$ de água destilada tamponada estéril. A partir desta diluição inicial a $10^{-1}$, preparava-se uma série de diluições decimais até $10^{-5}$ e a partir delas realizava-se o exame bacteriológico.

\section{Metodologia empregada}

Pesquisa de Salmonella 1,17 - Em condições assépticas pesavam-se $25 \mathrm{~g}$ do produto liquefeito e misturava-se a $225 \mathrm{ml}$ de caldo lactosado para pré-enriquecimento de Salmonella e, a seguir, procedia-se a incubação a $35-37^{\circ} \mathrm{C}$ durante 24 horas. Após esse período semeava-se $1 \mathrm{ml}$ da mistura nos caldo de enriquecimento de tetrationato de Kauffmann e de selenito e incubava-se a $43^{\circ} \mathrm{C}$ por 24 h. Após a incubação, a partir 
FALCÁ, D.P. et al. Exame microbiológico de sorvetes năo pastelrizados. Rev. Saúde públ., S. Paulo, $17: 2-8,1983$.

desses caldos de enriquecimento, semeavam-se placas de ágar SS e ágar Verde Brilhante e seguia-se a metodologia habitual para a caracterização de Salmonella ${ }^{15}$.

Contagem de bactérias aeróbicas ou facultativas mesófilas e psicrófilas ${ }^{1,21}$. Misturava-se $1 \mathrm{ml}$ de cada uma das diluições $\left(10^{-1}\right.$ a $\left.10^{-5}\right)$ a $20 \mathrm{ml}$ de ágar padrão fundido e resfriado a $40-45^{\circ} \mathrm{C}$, realizando em seguida a homogeneização e mantendo-se as placas em temperatura ambiente até a solidificação do ágar. A seguir, as placas eram incubadas a $35-37^{\circ} \mathrm{C}$ por $48 \mathrm{~h}$ para contagem de microrganimos mesófilos e a $7^{\circ} \mathrm{C}$ por 10 dias para a de psicrófilos.

Determinação do Número Mais Provável (NMP) de coliformes totais e fecais ${ }^{21}$. Inoculavam-se as diluições em 4 séries, contendo cada uma 3 tubos de caldo lactosado-bile-verde-brilhante a $2 \%$ com tubo de Durham e incubava-se a $35-37^{\circ} \mathrm{C}$ por $24-$ $-48 \mathrm{~h}$. Considerava-se a prova como positiva quando ocorria a presença de gás no tubo de Durham. A partir de cada tubo positivo semeava-se a superfície de ágar Eosina Azul de Metileno (EAM) em placas para a realização da prova confirmatória. Após incubação a $35-37^{\circ} \mathrm{C}$ por $24 \mathrm{~h}$, consideravam-se como positivas as placas contendo colônias com as características das de coliformes, ou sejam, negras, secas e chatas ou claras, convexas, brilhantes e com centro negro. A prova completa era realizada à partir das placas de ágar EAM positivas. Inoculava-se material de uma colônia típica de coliforme em caldo lactosado com tubo de Durham e em ágar simples inclinado. Após incubação a $35-37^{\circ} \mathrm{C}$ por $24-48 \mathrm{~h}$ verificava-se a produção de gás nos tubos de caldo lactosado e preparavam-se esfregaços à partir das culturas em ágar simples inclinado, os quais eram corados pelo método de Gram. A presença de bacilos Gram-negativos não esporulados e a produção de gás em caldo lactosado constituia a prova completa positiva para bactérias do grupo coliforme.

A partir dos tubos com prova presuntiva positiva para coliformes totais, transferia-se uma alçada para caldo EC, contendo tubo de Durham, para realizar-se a determinação do NMP de coliformes fecais. Incubava-se a $44,5^{\circ} \mathrm{C}$ por $24-48 \mathrm{~h}$. A presença de gás indicava prova positiva para coliformes fecais.

Para calcular-se o NMP empregava-se as tabelas convencionais 1,22 .

Contagem de Staphylococcus aureus 1,26. Semeava-se, $0,1 \mathrm{ml}$ de cada uma das diluições em ágar Baird Parker e incubava-se a $25-37^{\circ} \mathrm{C}$ por $48 \mathrm{~h}$. Contavam-se as colonias negras com halo transparente. A confirmação era realizada pela prova da coagulase e morfologia bacteriana pela coloração de Gram.

\section{RESULTADOS}

Não foram isoladas salmonelas em nenhuma de 24 amostras de sorvetes examinadas.

Os resultados das contagens totais de microrganismos mesófilos e psicrófilos e de Staphylococcus aureus, por grama, nas 24 amostras, são apresentados na Tabela 1.

A Tabela 2 apresenta o NMP de coliformes totais e de coliformes fecais por grama de sorvete.

\section{DISCUSSAO E CONCLUSOES}

O padrão estabelecido para comestiveis gelados, pela Comissão Nacional de Normas e Padrões para Alimentos ${ }^{23}$. tolera nesses produtos. no máximo 100 bactérias do grupo coliformes totais por grama e 200.000 por grama na contagem padrão em placa para bactérias mesófilas.

Analisando nossos resultados quanto a coliformes totais, verifica-se que apenas uma das amostras examinadas não se apresentava contaminada por germes desse grupo, enquanto que $66,6 \%$ estavam fora do padrão pois apresentavam contagens superiores a 100 microrganismos por grama. 
FALCAO, D.P. et al. Exame microbiológico de sorvetes não pastetrizados. Rev. Saúde públ., $\mathbf{S}$. Paulo, 17:2-8,1983.

T A B L A 1

Contagem total de microrganismos mesofilos e psicrófilos e de staphylococcus aureus por grama, em 24 amostras de sorvete.

\begin{tabular}{|c|c|c|c|c|c|c|}
\hline \multirow{2}{*}{$\begin{array}{l}\text { Número de } \\
\text { Microrganismos/g }\end{array}$} & \multicolumn{2}{|c|}{ Mesofilos } & \multicolumn{2}{|c|}{ Psicrófilos } & \multicolumn{2}{|c|}{ s. aureus } \\
\hline & $\begin{array}{l}\mathrm{n}^{9} \text { de } \\
\text { amostr'ts }\end{array}$ & $\%$ & $\begin{array}{l}\text { no de } \\
\text { amostras }\end{array}$ & $\%$ & $\begin{array}{l}\text { no de } \\
\text { amostras }\end{array}$ & $\%$ \\
\hline $0 \longmapsto 10$ & - & - & 18 & 75,00 & 20 & 83,33 \\
\hline $10 \quad-102$ & $-\cdot$ & - & 1 & 4,16 & 2 & 8,33 \\
\hline $10 \div 1-103$ & 2 & 8,33 & 3 & 12,50 & 1 & 4,16 \\
\hline $1031-104$ & 8 & 33,33 & 1 & 4,16 & 1 & 4,16 \\
\hline $104 \longrightarrow 10 \mathrm{~s}$ & 9 & 37,50 & 1 & 4,16 & - & - \\
\hline $10: \mid--10:$ & 3 & 12,50 & - & 一 & - & - \\
\hline $10: \square-107$ & 2 & 8,33 & $\cdots$ & - & -- & - \\
\hline
\end{tabular}

T A B E L A 2

Número Mais Provável de collformes totals e collformes fecais por grama, em 24 amostras de sorvete.

\begin{tabular}{|c|c|c|c|c|}
\hline \multirow{2}{*}{$\begin{array}{l}\text { Número de } \\
\text { Mierorganismos/g }\end{array}$} & \multicolumn{2}{|c|}{ Coliformes Totais } & \multicolumn{2}{|c|}{ Collformes Fecais } \\
\hline & ne & $\%$ & ne & $\%$ \\
\hline $0 \quad-10$ & 3 & 12,50 & 13 & 54,16 \\
\hline $10 \quad-102$ & 4 & 16,66 & 7 & 29,16 \\
\hline $102 \mid-103$ & 8 & 33,33 & 1 & 4,16 \\
\hline $103 \quad \longrightarrow$ & 8 & 33,33 & 3 & 12,50 \\
\hline
\end{tabular}

Sabe-se que "coliformes totais" sāo bons indicadores das condiçōes sanitárias dos alimentos, estando portanto, a maioria das amostras examinadas em condições sanitárias insatisfatórias.

Realizou-se também a contagem de collformes fecais, considerados melhores indicadores de poluição de origem fecal que os coliformes totais por serem especificos de fezes humanas $\mathrm{e}$ de animais de sangue quente, indicando, consequientemente, condições propícias para o encontro também de patógenos intestinais. Setenta e cinco por cento das amostras de sorvetes estavam contaminadas com microrganismos desse grupo, sendo observadas em algumas delas contagens superioras a 10.000 células por 
FALCAO, D.P. et al. Exame microbiológico de sorvetes não pasteurizados. Rev. Saúde públ., S. Paulo, 17:2-8,1983.

grama (Tabela 2), indicando com isso péssimas condições sanitărias de preparo e o perigo potencial à saúde pública que esses alimentos representavam. Joly 22 isolou, das amostras de sorvetes examinadas, estreptococos fecais, os quais também sāo usados como indicadores de contaminaçāo fecal. Os trabalhos de Chaineux e Jacquemim ${ }^{13}$ e de Chaineux e col.14 mostram em sorvetes examinados na Bélgica e Luxemburgo altas contagens de coliformes, acima dos padrões ali existentes para esse grupo. Annino e col.2 realizando análise microbiológica em sorvetes preparados industrialmente e artesanalmente, todos à base de leite ou frutas. em Nápoles, Itália, verificaram maiores percentagens de coliformes naqueles à base de leite e preparados de maneira artesanal.

Ainda dentro da família Enterobacteriacene decidiu-se verificar a presença de Salmonella, pois muitos são os relatos de surtos de gastrenterite ou febre tifóide ou mesmo de casos isolados de toxi-infecção, todos relacionados à transmissāo desse microrganismo por sorvetes 2,4-12,18,24,25. Mas nāo se isolou salmonela de qualquer amostra de sorvete examinada.

Microrganismos mesófilos aeróbicos ou facultativos foram isolados das 24 amostras de sorvetes sempre em número superior a 100 células por grama, sendo que cerca de $20,8 \%$ delas apresentavam contagens superiores ao padrão respectivo, ou seja, mais de $2.10^{5}$ células por grama. Todo alimento é considerado impróprio quando a população de microrganismos mesófilos viáveis é muito alta, mesmo não se sabendo se são ou não patogênicos; uma contagem alta indica condiçōes inadequadas de preparo, e também que o alimento apresenta condições que favorecem a ocorrência de patógenos mesófilos. Por outro lado, no que diz respeito à deterioração do alimento armazenado no refrigerador, a contagem de psicrófilos é mais importante que a de mesófilos, porque muitos organismos mesófilos morrem à temperaturas variáveis entre $5-15^{\circ} \mathrm{C}$ ou mais baixas. Os números de psicrófilos, conforme mostrado na Tabela 1, não são tão elevados quanto os de mesófilos; a maioria das amostras não apresentava esses organismos. Isto provavelmente ocorreu porque todos esses sorvetes sảo processados de maneira artesanal, em pequenas quantidades e praticamente consumidos no mesmo dia do seu preparo, não tendo portanto um perfodo longo de armazenamento como ocorre com aqueles preparados de maneira industrial. Em conseqüência, não houve tempo para multiplicação maior de psicrófilos, enquanto os mesófilos provavelmente se multiplicaram nos ingredientes empregados na preparaçào dos sorvetes.

Outra verificaçăo que realizamos foi a presença e contagem de Staphylococcus aureus, pois há relatos de intoxicação alimentar estafilocócica através da ingestão de sorvete contaminado ${ }^{19}$; pelo fato de estarmos analisando sorvetes não pasteurizados, a possibilidade de presença de Staphylococcus aureus e mesmo de sua enterotoxina, elaborada antes do congelamento, poderiam tornar os sorvetes examinados potencialmente perigosos à saúde do consumidor. Para exame de alimento nos quais há recomendação da pesquisa de Staphylococcus aureus, os padrōes referem como contagem máxima permitida $10^{2}$ a $10^{3}$ células por grama e, para outros, ausência total. A Tabela 1 mostra a presença desse microrganismo em cerca de $16,6 \%$ das amostras, em número variando de dez a mil células por grama, tornando esses sorvetes potencialmente perigosos à saúde do consumidor.

Os resultados do presente trabalho indicam, para a grande maioria dos sorvetes examinados, condições sanitárias inadequadas devido à presença de microrganismos mesófilos em grande número, de psicrófilos e de coliformes totais. Por outro lado, a presença de coliformes fecais e de Staphylococcus aureus, em alguns dos sorvetes, torna-os potencialmente perigosos à saúde do consumidor, pelo fato de entre os primeiros poderem estar presentes bactérias ou vírus causadores de doença e os segundos por poderem produzir enterotoxina. 
FALCAO, D.P. et al. Exame microbiológico de sorvetes não pasteurizados. Rev. Saúde públ, S. Paulo, 17:2-8,1983

FALCÃ, D. P. et al. [Microbiological examination of non pasteurized ice cream]. Rev. Saúde públ., S. Paulo, $17: 2-8,1983$.

ABSTRACT: A microbiological examination was made on 24 samples of non pasteurized, non industrial ice cream, all made with milk collected from 12 different ice cream shops in Araraquara, SP, Brazil. For the study, two samples were collected 15 days apart, from each store. The following tests were made using ice-cream samples: presence or absence of Salmonella; counts of mesophilic an psichrophilic bacteria and Staphylococcus aureus and verification of the Most Probable Number (MPN) of enteric organisms (faecal coliforms and other coliforms). The techniques used were the conventional ones used in such calculations. All samples were negative for Salmonella while about $16.6 \%$ showed the presence of Staphylococcus aureus. There were deteriorative microorganisms and faecal coliforms present in varying proportions.

UNITERMS: Ice-cream. Food contamination. Food microbiology.

\section{REFERENCIAS BIBLIOGRAFICAS}

1. AMERICAN PUBLIC HEALTH ASSOCIATION. Committee on Microbiological Methods for Foods. Compendium of methods for the microbiological examination of foods. Washington, D.C., 1976.

2. ANNINO, I.; BOCCIA, A.; DEL PRETE, U. \& MONTANARO, D. Controllo igienico della prodozione dei gelati in vendita nella cittá di Napoli. Nuovi Ann. Ig. Microbiol., 28:365-85,85, 1977.

3. ARMSTRONG, R.W.; FODOR, T.; CURLIN, G.T.; COHEN, A.B.; MORRIS, G.K.; MARTIN, W.T. \& FEELDMAN, J. Epidemic Salmonella gastroenteritis due to contaminated imitation ice cream. Amer. J. Epidem., 91:300-7, 1970.

4. CENTER FOR DISEASE CONTROL. Foodborne \& Waterborne Disease Outbreaks. Annual Summary 1973. Atlanta, 1974.

5. CENTER FOR DISEASE CONTROL. Foodborne \& Waterborne Disease Outbreaks. Annual Summary 1974. Atlanta, 1976.

6. CENTER FOR DISEASE CONTROL. Foodborne \& Waterborne Disease Outbreaks. Annual Summary 1975. Atlanta, 1976.

7. CENTER FOR DISEASE CONTROL. Foodborne \& Waterborne Disease Outbreaks. Annual Summary 1976. Atlanta, 1977.
8. CENTER FOR DISEASE CONTROL. Foodborne \& Waterborne Disease Surveillance. Annual Summary 1977. Atlanta, 1979.

0. CENTER FOR DISEASE CONTROL. Foodborne \& Waterborne Disease Surveillance. Annual Summary 1978. Atlanta, 1979.

10. CENTER FOR DISEASE CONTROL. Salmonella Surveillance. Report n* 121. Annual Summary 1973. Atlanta, 1974.

11. CENTER FOR DISEASE CONTROL. Salmonella Survelllance. Report no 125. Annual Summary 1974. Atlanta, 1975.

12. CENTER FOR DISEASE CONTROL. Salmonella Surveillance. Annual Summary 1977. Atlanta, 1979.

13. CHAINEUX, J. \& JACQUEMIN, J. Examens bactériologiques des glaces de consommation: résultats et considérations. Arch. belg. Méd. soc., 3:153-7, 1973.

14. CHAINEUX, J.; PAWELKOWSKI, J.; HENVAUX, J.P.; JACQUEMIN, J.; JACQUES, C. ; ARNOUD, F. \& GERARD, M.I. Examéns bactériologiques des glaces da consommation. Résultats et considerations. Arch. belg. Med. soc., 35:245-50, 1977.

15. EDWARDS, P.R. \& EWING, W.H. Identification of Enterobacteriaceae. 3rd ed. Minneapolis, Burgess Publishing, 1972. 
F'ALCAO, D.P. et al. Exame microbiológico de sorvetes não paste. rizados. Rev. Saúde públ., $\mathbf{S}$. Paulo, $17: 2-8,1983$.

16. FREZZA, L.; CALISTO, M.L. \& MILICI, G. La colimetria nei gelati: confronto tra il metado "Bacto-strip" e il metado all' Agar desossicolato. Rev. ital. Ig., $28: 641-4,1968$.

17. GALTON, M.M. ; MORRIS, G.K. \& MARTIN, W.T. Salmonellae in foods and feeds: review of isolation and recomended procedures. Atlanta, Communicable Disease Center, 1968.

18. GUNN, R. \& MARKAKIS, G. Salmonellosis associated with home made ice cream: an outbreak report and summary of outbreaks in the United States in 1966 to 1976. J. Amer. med. Ass., 240:1885-6, 1978.

19. HEALTH AND WELFARE CANADA. Health Protection Branch. Foodborne Disease in Canada: annual summary 1973. Otawa, 1976.

20. HEALTH AND WELFARE CANADA. Health Protection Branch. Foodborne Disease in Canada: annual summary 1975. Otawa, 1979.

21. INTERNATIONAL COMMITTEE ON MICROBIOLOGICAL SPECIFICATION FOR FOOD (ICMSF). Miero-organisms in foods. I - Their significance and methods of enumeration. 2nd ed. Toronto, University Press, 1978.
22. JOLY, S. Microbiologia de alimentos. I Isolamento de microrganismos de sorvetes de lábricas. O Bolo, 63:41-4, 1971.

23. MINISTERIO DA SAUDE. Comissão de Normas e Padrōes para Alimentos. Resolução 13/78 de março de 1978. Díario Oficial, Brasilia, 25 julho 1978. Secção I, parte 1, p. 269-73.

24. TAUNAY; A.E. Diagnóstico bacteriológico das salmonelas de origem animal, sua importancia e frequência no município de Săo Paulo. Rev. Inst. Adolfo Lutz, $28: 43-69,1968$.

25. TAYLOR Jr., A.; SANTIAGO, A.; GONZALES-CORTES, A. \& GANGAROSA, E.J. Outbreak of typhoid fever in Trinidad in 1971 traced to a commercial ice cream product. Amer. J. Epidem., 100: 150-7, 1974.

26. UNITED STATES. Departament of Health, Education and Welfare. Frood and drug administration bacteriological analytical manual. 4th ed. Washington, D.C., 1976.

Recebido para publicaşão em 19/05/1982

Aprovado para publicagão em 30/09/1982 